\title{
Genetic and Biological Diversity of Trichoderma stromaticum, a Mycoparasite of the Cacao Witches'-Broom Pathogen
}

\author{
Jorge T. de Souza, Alan W. V. Pomella, John H. Bowers, \\ Carlos P. Pirovani, Leandro L. Loguercio, and K. Prakash Hebbar
}

First author: Wye Research and Education Center, University of Maryland, Queenstown 21658; first and sixth authors: U.S. Department of Agriculture-Agricultural Research Service, Sustainable Perennial Crops Laboratory, BARC-West, Beltsville 20705; second author: Almirante Cacau Agrícola Comércio e Exportação Ltda, Caixa Postal 55, 45630-000 Itajuípe, BA, Brazil; third author: Bowers Consulting Services, Laurel, MD 20707; fourth and fifth authors: Universidade Estadual de Santa Cruz, BR 415, Km 16, Ilheus, BA, 45662-000, Brazil; and sixth author: Masterfoods, Hackettstown, NJ 07840.

Current address of J. T. de Souza: CEPLAC/CEPEC/SEFIT, Caixa Postal 7, Km 22 Rodovia Ilheus-Itabuna, $45600-970$ Itabuna, BA, Brazil. Current address of J. H. Bowers: Maryland Department of Agriculture, Plant Protection and Weed Management, Annapolis 21401. Accepted for publication 28 August 2005.

\begin{abstract}
de Souza, J. T., Pomella, A. W. V., Bowers, J. H., Pirovani, C. P., Loguercio, L. L., and Hebbar, K. P. 2006. Genetic and biological diversity of Trichoderma stromaticum, a mycoparasite of the cacao witches'-broom pathogen. Phytopathology 96:61-67.

The witches'-broom disease, caused by the basidiomycete Crinipellis perniciosa, is the most limiting factor for cacao cultivation in Brazil. Trichoderma stromaticum is a mycoparasite of the witches'-broom pathogen of cacao that is currently being applied in the field to manage the disease in Bahia State, Brazil. In this work, molecular and traditional methods were used to study the genetic and biological diversity of this mycoparasite. Ninety-one isolates, mostly collected from farms not sprayed with the fungus, were analyzed by amplified fragment length

other characteristics, including growth on agar media at different temperatures and sporulation on infected stem segments (broom pieces) and rice grains. Group II favors higher temperatures compared with group I. The genetic and biological differences of the isolates, however, were not evident in field experiments, where sporulation was evaluated on the surface of brooms under natural conditions. Our results show that there is considerable genetic and biological diversity within T. stromaticum in Bahia and other cacao-growing regions of South America that are affected by the witches'-broom disease. This diversity could be explored in the development of efficient biological control agents against the disease. Factors that may affect the application and performance of this biocontrol agent in the field, such as sporulation on rice substrate and on the brooms and growth at various temperatures, are discussed.
\end{abstract} polymorphisms (AFLP), which showed that two genetic groups (I and II) of T. stromaticum occur in Bahia State. This classification of T. stromaticum into two distinct AFLP groups was also in agreement with several
Additional keywords: fingerprinting, Theobroma cacao.
Cacao (Theobroma cacao) originates from the Amazonian rain forest, and until the $1920 \mathrm{~s}$, most of the world's supply of cacao beans came from South America, notably Ecuador and Bahia State in Brazil (12). Fungal diseases, mainly witches'-broom disease caused by the basidiomycete Crinipellis perniciosa, were responsible for a significant decline in production in both countries. In Bahia, cacao is traditionally grown under native shade trees, a system known as cabruca. This environmentally friendly farming system can help to protect the remains of the endangered Atlantic forest of Bahia State. By 1986, cacao farming was the basis of Bahia State's economy with the production of 400,000 tons of cacao beans. With the outbreak of witches'-broom disease in 1989 , production dropped by $75 \%$ in the last 14 years $(1,15)$. This has led to a switch in the prevalent economic activities, with two major consequences: decrease of the cacao planted area and consequent destruction of endangered forest remains, as well as a severe increase in social problems (6).

Corresponding author: J. T. de Souza; E-mail address: jorge@ cepec.gov.br

* The $\boldsymbol{e}$-Xtra logo stands for "electronic extra" and indicates that the online version contains supplemental material not included in the print edition. The online version contains a table showing the binary data obtained in the AFLP analysis of Trichoderma stromaticum.

DOI: 10.1094/PHYTO-96-0061

(C) 2006 The American Phytopathological Society
Basidiospores of the hemibiotrophic pathogen C. perniciosa are able to infect all meristematic tissues of cacao, including pods and flower cushions. Infected tissues suffer hypertrophy and hyperplasia that result in loss of apical dominance and the formation of the brooms, which initially are green and ultimately die (22). Dead brooms and infected pods containing the pathogen are sources of inoculum, the basidiospores, which are produced inside mushroom-like basidiocarps.

Control of the disease cannot be completely achieved by a single method. The most commonly used control strategy includes the removal of affected plant tissues (phytosanitation), followed by applications of copper-based fungicides. Phytosanitation is very costly and labor-intensive. Research has shown that under Amazonian conditions, removal of $95 \%$ of the brooms leads to a $50 \%$ reduction in pod losses (16). Ideally, phytosanitation should be applied by all farmers in a given area for satisfactory control. Neglected farms are a constant source of inoculum to actively producing areas. Besides being expensive, application of chemical fungicides brings up the constant concern of impacting human health and the environment. Cacao cultivars resistant to the disease are under development, but because of the plant's long life cycle, breeding programs are slow and there are many difficulties to combine resistance with other traits of interest, such as productivity and flavor. Moreover, overcoming of resistance is a constant threat to the breeding program.

Biological control is an attractive strategy to manage this disease. It is frequently one of the safest and most affordable control 
methods available. Research has led to the identification of several organisms with potential to control witches'-broom disease $(2,3)$. Among them is a recently characterized species, Trichoderma stromaticum (18), a mycoparasite of $C$. perniciosa with great potential for biological control. This antagonist colonizes dead brooms and kills $C$. perniciosa, drastically reducing the production of basidiospores and accelerating broom decomposition (2). One study showed that application of T. stromaticum spores reduced basidiocarp formation by $99 \%$ on brooms on the ground and by $56 \%$ on brooms in cacao trees (4). T. stromaticum was originally isolated from brooms in the Northern State of Pará (Amazon region), and one isolate known as TVC (AM7 in this study) was later introduced into Bahia State, which is the largest Brazilian cacao-producing area (4). The Brazilian institute for cacao research (CEPLAC-Comissão Executiva do Plano da Lavoura Cacaueira) is producing spores of the fungus on rice grains and distributing it to be applied on cacao farms. Sanogo et al. (19), working with one isolate of $T$. stromaticum (TVC) under laboratory conditions, showed that temperature and relative humidity greatly influence the antagonist's activity. Other factors such as genetic background of the isolates and ability to establish and spread in cacao farms could affect their performance in the field. Following its introduction in Bahia, the fungus could be isolated from cacao farms never sprayed, indicating that it might be disseminating within this area (A. W. V. Pomella, unpublished data).

In this study, we used amplified fragment length polymorphisms (AFLP) to analyze the genetic diversity of 91 isolates of T. stromaticum collected mainly from neglected cacao farms in the State of Bahia. Among these isolates, 25 were obtained from the Amazonian region, including samples from Brazil, Colombia,

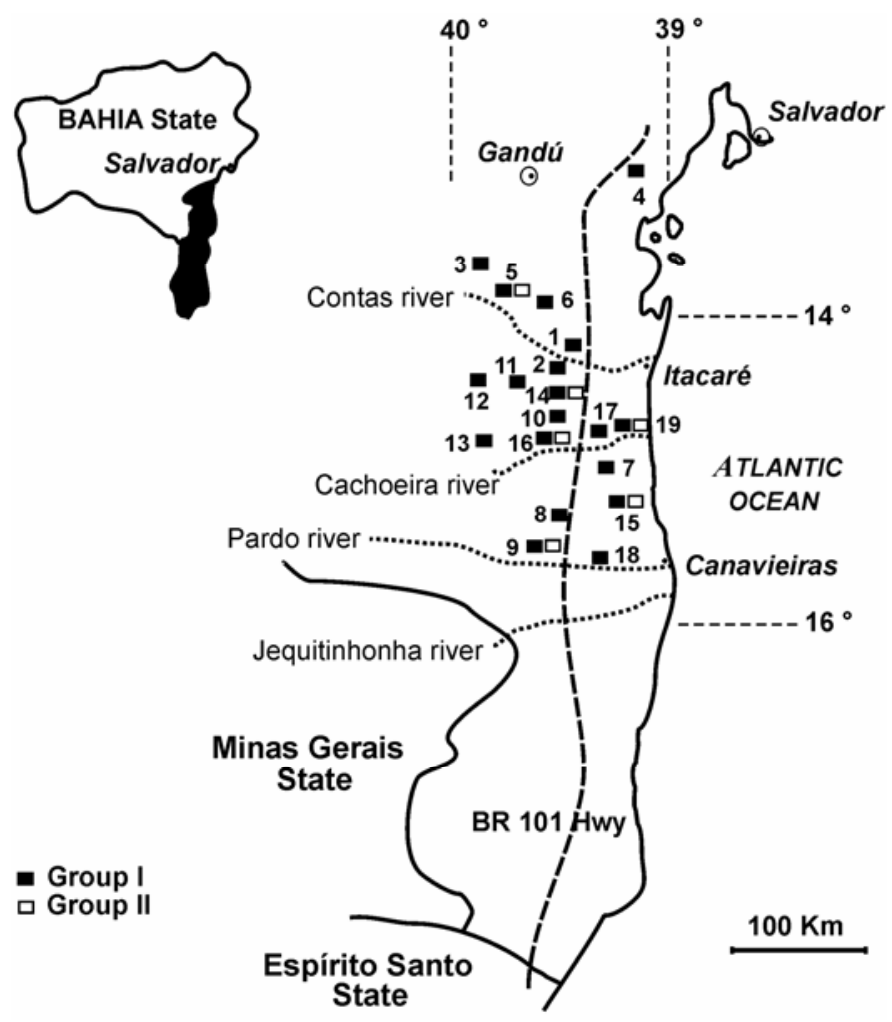

Fig. 1. Map of the Southern region of Bahia State showing the distribution of Trichoderma stromaticum. The small panel at the top left corner shows the map of the Bahia State, with the filled part representing the area detailed in the figure. Large numbers at the end of dashed lines indicate the south latitudes and western longitudes of the region; small numbers (1 to 19) indicate the sample-collecting sites. The geographic distribution of T. stromaticum isolates is shown by empty and filled squares, which also distinguish the two genetic groups identified by amplified fragment length polymorphism (AFLP) analysis (AFLP analysis described in text). and Ecuador. We concentrated our sampling on neglected farms to avoid overrepresenting strain AM7 which was applied on commercially active farms. AFLP analysis with fluorescence dyelabeled markers was performed with a capillary electrophoresis genetic analyzer. Sequencing of the internal transcribed spacer (ITS) was used to confirm the identity of selected isolates of T. stromaticum. Growth rate on different agar media and at different temperatures, and sporulation on brooms at different temperatures were studied in relation to the genetic diversity of T. stromaticum. We also studied the sporulation of selected isolates on rice grains, since this substrate is being used to produce inoculum of T. stromaticum for field applications. Field experiments were done to study the sporulation of 57 isolates on brooms in cacao farms in Bahia.

\section{MATERIALS AND METHODS}

Sampling. Dead parts of cacao plants, including brooms and pods from the ground and brooms from the canopy, were collected from plantations in the Southern region of Bahia State. Most isolates used in this study were obtained from dead brooms (collected either on the ground or hanging on cacao trees) and from decomposing pod husks from the ground. However, isolate BA66 was isolated from within the bark of a cupuassu (Theobroma grandiflorum) tree; isolate AM3 was obtained from the cortex of the trunk of a cacao tree; isolate AM1 from a diseased cacao pod (chirimoya); and isolate BA72 from the surface of a cacao leaf. Isolate AM7, obtained in Pará State and the only isolate introduced into Bahia State and sprayed on commercially active farms, was also included in the analysis. The States of Pará and Rondônia are approximately 2,300 and 3,700 km from Bahia, respectively. A total of 378 samples were collected mainly from abandoned farms where T. stromaticum was never applied for biological control purposes. This sampling procedure attempted to cover the whole cacao-growing area of South Bahia (Fig. 1). Samples were transferred to plastic bags containing a moist paper towel and incubated at $25^{\circ} \mathrm{C}$ for up to 20 days. Samples showing typical sporulation of T. stromaticum (19) were used for purification through the selection of individual colonies on potato dextrose agar (PDA) medium.

Isolates and culture conditions. $T$. stromaticum was routinely grown on corn meal agar (CMA) (Difco Laboratories, Detroit, MI) medium. Single-spore cultures of all isolates were prepared by plating diluted conidial suspensions onto Trichoderma semiselective medium (14). For DNA extractions, all isolates were grown on potato dextrose broth for 4 days. The 91 isolates used in this study are shown in Table 1 . Isolate GLI-39 of $T$. virens was used as a reference strain for comparison purposes. For spore production, isolates were grown on CMA for 4 days at $25^{\circ} \mathrm{C}$. Spores were scraped from the plates and the concentration was adjusted with the use of a hemacytometer. All isolates were stored in $10 \%$ glycerol at $-80^{\circ} \mathrm{C}$. For every experiment, fresh plates were obtained by culturing the isolates from the $-80^{\circ} \mathrm{C}$ stocks.

AFLP analyses. Mycelium of single-spore cultures was crushed with small pestles in microcentrifuge tubes, and DNA was extracted with the PUREGE Kit (Minneapolis, MN). Fluorescent dye-labeling and signal detections were performed on a CEQ 8000 (Beckman-Coulter, Fullerton, CA) genetic analyzer. The experimental procedures were performed with the AFLP Microbial Fingerprinting Kit (Perkin-Elmer Applied Biosystems, Foster City, $\mathrm{CA}$ ), following the manufacturer's recommendations. Samples containing $150 \mathrm{ng}$ of genomic DNA from each isolate were digested with 5.0 units of EcoRI and 1.0 units of MseI (New England Biolabs, Beverly, MA) and ligated overnight to EcoRI (5'CTCGTAGACTGCGTACC-3'; 3'-CATCTGACGCATGGTTAA5') and MseI (5'-GACGATGAGTCCTGAG-3'; 3'-TACTCAGGACTCAT-5') AFLP adaptors in a single step at room temperature. For the pre-selective amplification, $4 \mu$ of the 20 -fold diluted 
ligation mixture was amplified for 20 cycles of $30 \mathrm{~s}$ at $94^{\circ} \mathrm{C}$, $1 \mathrm{~min}$ at $56^{\circ} \mathrm{C}$, and $1 \mathrm{~min}$ at $72^{\circ} \mathrm{C}$, using the GeneAmp $9700 \mathrm{PCR}$ System (Applied Biosystems). Products from the pre-selective amplification were diluted 20 -fold and used as templates for the selective amplification (20).

For selective amplification and subsequent detection on the CEQ 8000 System, EcoRI primers with two different selective nucleotides at their $3^{\prime}$ end (EcoRI-AG $=5^{\prime}$-GACTGCGTACCAATTCAG-3' and EcoRI-AC $=5^{\prime}$-GACTGCGTACCAATTCAC-3') were labeled with a WellRED active ester dye added to their 5' ends (Research Genetics Inc., Huntsville, AL). Three unlabeled $M s e$ I primers with one or two selective nucleotides at their $3^{\prime}$ end (MseI-C = 5'-GATGAGTCCTGAGTAAC-3', Mse I-G = 5'GATGAGTCCTGAGTAAG-3' and $M s e$ I-CA = 5'-GATGAGTCCTGAGTAACA-3') were used. Primer combinations used were $E c o$ RI-AG+MseI-C, EcoRI-AG+MseI-CA, and EcoRI-AC+MseIG. Amplification conditions consisted of an initial denaturation step at $94^{\circ} \mathrm{C}$ for $2 \mathrm{~min}$ followed by 10 cycles at $94^{\circ} \mathrm{C}$ for $20 \mathrm{~s}$, primer annealing consisted of a $1^{\circ} \mathrm{C}$ per cycle step-down starting at $66^{\circ} \mathrm{C}$ for $30 \mathrm{~s}$, and $72^{\circ} \mathrm{C}$ for $2 \mathrm{~min}$ for DNA extension, followed by 20 cycles of $94^{\circ} \mathrm{C}$ for $20 \mathrm{~s}, 56^{\circ} \mathrm{C}$ for $30 \mathrm{~s}$, and $72^{\circ} \mathrm{C}$ for $2 \mathrm{~min}$, and a final hold at $60^{\circ} \mathrm{C}$ for $30 \mathrm{~min}$ (GeneAmp $9700 \mathrm{PCR}$ system). The products from this selective amplification were prepared for analysis by diluting 30-fold in Loading Solution (Beckman-Coulter), which included the 400-bp DNA size standard. Fragment separation and detection was performed with the CEQ 8000 Genetic Analysis system, using capillary electrophoresis on each sample, beginning with a 30 -s electrophoretic injection at $2 \mathrm{kV}$ and a 35 -min separation at $6 \mathrm{kV}$. Fragment data were analyzed using the CEQ 8000 software with the analytical parameters calibrated to detect peaks with a slope of 5 and $10 \%$ of the height of the second highest peak. The maximum bin width was adjusted to 1.00. Each sample was scored as "1" for each bin if a fragment of that size was present, and as " 0 " if not. A table containing this binary information was used to calculate Jaccard's pairwise coefficients of similarity as implemented in the program FreeTree version 0.9.1.50 (7). Data from all primer combinations were analyzed separately and combined. Cluster analysis by the unweighted-pair grouping method with arithmetic mean algorithm and bootstrap analysis with 1,000 resamplings were performed using the FreeTree software. The dendrograms were visualized and edited using TreeView version 1.6.6 (13).

Primers were chosen among 15 combinations tested in the CEQ system. These combinations were chosen due to the high number of polymorphic peaks obtained. Reproducibility of the AFLP analyses was tested for a subset of 10 isolates, two DNA isolations, and three primer combinations.

Sequencing of the ITS region. Primers ITS1 and ITS4 (23) were used to amplify approximately 577 bp fragments of the ribosomal DNA (rDNA), including the 5.8S gene and the flanking intergenic transcribed spacers ITS1 and ITS2. Polymerase chain reaction (PCR) was performed in 50- $\mu$ l reactions containing $6 \mu \mathrm{l}$

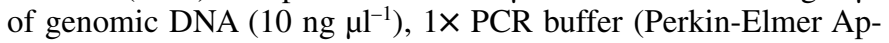
plied Biosystems), $200 \mu \mathrm{M}$ of each dNTP (Promega, Madison, WI), 2 units of Taq polymerase (Promega), $1.5 \mathrm{mM} \mathrm{MgCl}_{2}$ (Promega), and $20 \mathrm{pmol}$ of each primer. Amplification products were purified by a PCR purification kit (Qiagen, Valencia, CA) and directly sequenced by using an automated DNA sequencing system (ABI-3100; Applied Biosystems), using standard protocols (17). Nucleotide sequences were aligned using CLUSTAL W version 1.81 (21). Phylogenetic analysis was performed with the neighbor-joining method, using the model of Jukes and Cantor (9), and bootstrap analysis with 1,000 resamplings as implemented in the program Mega version 2.1 (11). Phylogenetic trees were edited and visualized in the TreeView program. Nucleotide sequences were deposited in GeneBank under the following accession numbers: AM3 (AY856833), AM13 (AY856834), BA66 (AY856835), BA34 (AY856836), BA3 (AY856837), AM7
(AY856838), BA28 (AY856839), and AM14 (AY856840). Additional rDNA sequences from $T$. stromaticum obtained from the database for comparison purposes were as follows: GJS 97-179 (AF098287), GJS 97-180 (AF097911), GJS 97-181 (AF097910), GJS 97-182 (AF097912), GJS 97-183 (AF097913), and T. virens GLI 39 (AF099005) (18).

Growth and sporulation experiments. A total of 91 isolates of $T$. stromaticum were grown on PDA and CMA at 25, 30, and $35^{\circ} \mathrm{C}$. Mycelial growth was recorded daily until the plate was fully covered and sporulation was visually recorded after 14 days on both media and all temperatures. The experiment had four replicates per treatment (isolates) and was done twice.

For the experiment on sporulation on rice grains, 30 isolates, 17 from group I (BA11, BA12, BA13, BA17, BA24, BA26, BA27, BA28, BA32, BA42, BA47, BA50, BA58, BA59, BA73, BA75, and AM13) and 13 from group II (BA29, BA65, BA66, BA69, AM1, AM2, AM3, AM4, AM5, AM6, AM7, AM11, and AM14), were selected based on their AFLP profile. Autoclavable plastic bags were filled with $100 \mathrm{~g}$ of rice and $70 \mathrm{ml}$ of water. Bags were autoclaved twice on two consecutive days and inoculated with $6 \mathrm{ml}$ of spore suspensions $\left(10^{6}\right.$ spores $\left.\mathrm{ml}^{-1}\right)$ of each strain used. After 10 days of incubation, 1-g samples from each bag were collected, individually transferred to 50-ml tubes containing $20 \mathrm{ml}$ of water, and shaken vigorously for $5 \mathrm{~min}$ to dislodge the spores, and the number of conidia in the suspensions was determined individually with the use of a hemacytometer. The experiment had four replicates (bags) per treatment (isolate) and was repeated twice.

Brooms containing live mycelium of $C$. perniciosa were cut into pieces of approximately $3 \mathrm{~cm}$ and were immersed for $15 \mathrm{~min}$ in suspensions containing $10^{6}$ spores $\mathrm{ml}^{-1}$ of each of the 30 iso-

TABLE 1. Isolates of Trichoderma stromaticum used in this study, their geographical origin and amplified fragment length polymorphism (AFLP) group classification

\begin{tabular}{lllcl}
\hline \multicolumn{1}{c}{ Local of origin $^{\mathrm{a}}$} & $\begin{array}{c}\text { Isolate } \\
\text { identification }\end{array}$ & $\begin{array}{c}\text { No. of } \\
\text { isolates }\end{array}$ & Genetic group \\
\hline 1 & Ubaitaba & BA1 to BA5 & 5 & GI \\
2 & Aurelino Leal & BA6 & 1 & GI \\
3 & Ipiaú & BA7 & 1 & GI \\
4 & Ituberá & BA8 to BA18 & 11 & GI \\
5 & Ubatã & BA19 to BA22 & 4 & GI (2), GII (2) \\
6 & Ibirapitanga & BA23 & 1 & GI \\
7 & Buerarema & BA24 to BA25 & 2 & GI \\
8 & Arataca & BA26 & 1 & GI \\
9 & Camacã & BA27 to BA29 & 3 & GI (2), GII (1) \\
10 & Itajuípe & BA30 to BA33 & 4 & GI \\
11 & Inema & BA34 to BA38 & 5 & GI \\
12 & Coaraci & BA39 to BA41 & 3 & GI \\
13 & Ibicaraí & BA42 to BA45 & 4 & GI \\
14 & Uruçuca & BA46 to BA58 & 13 & GI (10), GII (3) \\
15 & Una & BA59 to BA63 & 5 & GI (2), GII (3) \\
16 & Lomanto Jr. & BA64 to BA68 & 5 & GI (3), GII (2) \\
17 & Itabuna & BA69 & 1 & GI \\
18 & Mascote & BA70 & 1 & GI \\
19 & Ilhéus & BA71 to BA77 & 7 & GI (5), GII (2) \\
20 & Medicilândia (PA) & AM1 to AM6 & 6 & GII \\
21 & Belém (PA) & AM7 to AM11 & 5 & GII \\
22 & Ouro Preto (RO) & AM12 & 1 & GII \\
23 & Paraíso (Colombia) & AM13 & 1 & GI \\
24 & Pichilingue (Ecuador) & AM14 & 1 & GII \\
\hline
\end{tabular}

a The entries 1 to 19 correspond to the locations in Bahia State, as shown in Figure 1; PA and RO indicate the Brazilian States of Pará and Rondônia, respectively.

${ }^{b}$ BA indicates the Bahian origin of the isolate, whereas AM corresponds to reference strains obtained from the Amazonian region, including the Brazilian States of Rondônia and Pará, Colombia, and Ecuador. AM7 is the only isolate known to have been introduced into Bahia and used in biocontrol treatments.

${ }^{c}$ Group I (GI) and Group II (GII) were defined on the basis of AFLP analyses. The number of isolates in each group is in parentheses. 
lates of T. stromaticum used in the rice sporulation experiment described above. Each replicate consisted of seven broom pieces that were placed in a petri plate with moist filter paper and transferred to a desiccator adjusted to $80 \%$ relative humidity with a saturated solution of $\mathrm{NaCl}$ inserted in the humidity chamber at the bottom of the desiccator (19) and incubated at 25 or $30^{\circ} \mathrm{C}$. After 5 days of incubation, the number of spores produced on the surface of the brooms was evaluated by weighting them individually and immersing each broom in 50-ml tubes containing $20 \mathrm{ml}$ of water and hand-shaking the tubes for 5 min to dislodge the spore masses. The number of spores in the suspension was determined microscopically with the use of a hemacytometer. The emergence of typical white mycelium of $C$. perniciosa at the ends of the broom pieces was indicative of its survival and was recorded before the determination of the number of spores. The experiment had four replicates and was performed twice.

Sporulation of $\boldsymbol{T}$. stromaticum under field conditions. The trial was performed in 2003 at the farm of Almirante Cacau Inc., located at the community of Barro Preto, Bahia State, Brazil. Dried brooms were sprayed near to run-off with standardized spore suspensions from each of the 57 evaluated isolates, which included 48 members of the group I (BA1, BA2, BA4, BA6-BA8, BA10-BA15, BA17, BA19, BA20, BA23-BA28, BA30-BA49, BA51, BA60, BA64, and BA67-BA70) and nine from group II (AM6, AM7, BA21, BA22, BA29, BA52, BA53, BA65, and BA66) as defined by the AFLP analysis. A lower number of isolates from group II was used because we did not want to introduce into Bahia isolates from the Amazonian region and from other countries, areas where most isolates from group II came from (Table 1). Sucrose at 2\% (wt/vol) and the mineral oil OPPA (Petrobras, Rio de Janeiro, Brazil) at $2 \%$ (vol/vol) were added to the spore suspensions $\left(10^{6}\right.$ spores $\left.\mathrm{ml}^{-1}\right)$ as adjuvants. Detached brooms were sprayed with a back-pack sprayer (Guarany, Itu, SP, Brazil). Control brooms were sprayed only with water and adjuvants. After spraying, brooms were taken to a cacao plantation and placed on 1.5-m-high stands, which were spaced $3 \mathrm{~m}$ from one another. T. stromaticum sporulation over the broom surface was visually evaluated three times a week for each broom for 3 months. Sporulation data for isolates from groups I and II after 2 months of field evaluation were used for the statistical analysis and were based on the percentage of brooms per isolate in which sporulation was detected. The second month was chosen because sporulation by most isolates was concentrated at this period. The experiment was designed in randomized blocks with three replicates, each consisting of seven brooms per isolate per block. The experiment was repeated twice.

Statistical analysis. To evaluate data from the experiments on growth on agar media and sporulation on rice as well as on broom pieces in the laboratory and brooms in the field, isolates were classified into group I or group II according to their AFLP profile. Prior to analysis, all data sets were tested for normality and homogeneity of variances (SAS Institute, Cary, NC). Data sets that did not present a normal distribution were analyzed with the one-way nonparametric analysis of variance of Kruskal-Wallis and the comparison of means was done by the Wilcoxon's twosample test (SAS Institute). All experiments were analyzed separately.

\section{RESULTS}

Distribution of $\boldsymbol{T}$. stromaticum. Most isolates characterized in this study were collected from abandoned farms where cacao farmers had never applied T. stromaticum. A total of 378 samples were collected from 20 geographic locations (Fig. 1, Table 1), with T. stromaticum present in an average of $17.5 \%$ of the samples (brooms and pods). The fungus appeared to be widely distributed in the whole cacao-producing region and was found at all collection sites with the exception of the municipality of
Gandú (Fig. 1). T. stromaticum group I (described under genetic diversity) occurred at all 19 collection sites, whereas group II was found at six collection sites. These results indicate that group I is more disseminated in Bahia than group II.

Genetic diversity of $\boldsymbol{T}$. stromaticum. Molecular methods were used to study the genetic diversity of the antagonistic fungus T. stromaticum in Bahia State (Fig. 1). Some isolates from the Brazilian States of Rondônia and Pará, and from Ecuador and Colombia were used for comparison purposes. To study the genetic diversity within $T$. stromaticum, an extensive AFLP analysis was performed. AFLP patterns were consistent, since more than $99.5 \%$ of the amplifications from replicate DNA extractions of the same isolate produced the same patterns in the CEQ system. From a total of 210 peaks obtained from 60 amplifications (10 isolates, two DNA isolations, and three primer combinations), one band obtained in one of the amplifications could not be repeated (data not shown). Only consistent peaks were used in the analyses. A total of 144 polymorphic peaks were scored in the CEQ system with sizes varying from 62 to $400 \mathrm{bp}$.

Results of the AFLP analysis with the CEQ system (Fig. 2) allowed us to establish that two major genetic groups of T. stromaticum are associated with the witches'-broom pathogen in Bahia. Out of the 91 isolates analyzed, 66 were classified as group I and 25 as group II. The separation into group I and II was strongly supported by a bootstrap value of $100 \%$ (Fig. 2). All isolates from the States of Pará and Rondônia and from Ecuador, including $\mathrm{AM} 7$, the isolate introduced in Bahia State and used for biocontrol treatments, were classified as group II. Isolate AM13 originated from Colombia and was the only representative of group I found outside Bahia, indicating that members of this genetic group are not exclusively found in Bahia State. The analysis revealed the existence of one subgroup composed of isolates BA27 and BA28 within group I, as indicated by the significant bootstrap value. On the other hand, four subgroups were present within group II, the first formed by isolate AM14; the second composed by AM1, AM7, AM9, AM12, and all isolates from Bahia; the third formed by AM3; and the fourth including AM4 and AM5 (Fig. 2). In general, the AFLP analysis revealed a lower level of diversity among group I isolates, with many subtle differences being nonsignificant based on bootstrap values lower than $70 \%$, whereas for isolates in group II, the level of diversity was higher (Fig. 2). These results were confirmed by the similarity levels that varied from 79 to $100 \%$ within group I and from 69 to $100 \%$ within group II, whereas the similarity between groups I and II varied from 57 to $69 \%$. The similarity between both groups and T. virens varied from 4 to $5 \%$ (data not shown).

Molecular identification of $\boldsymbol{T}$. stromaticum. Sequence analyses for eight strains (four each from AFLP groups I and II) was done to confirm species identity, which initially had been done based solely on morphological parameters. Comparison of $577 \mathrm{bp}$ fragments of rDNA sequences, which included the 5.8S gene and the flanking ITS1 and ITS2 regions, with reference sequences from public databases, showed that they were very similar. The percentage of identity between sequences of $T$. virens, used as a reference strain, and the other isolates ranged from 94.4 to $95 \%$, and the identity among T. stromaticum isolates varied from 99.3 to $100 \%$ (data not shown). These studies confirmed the isolate's identity as T. stromaticum. In these analyses no grouping among the $T$. stromaticum isolates was observed.

Biological diversity among $T$. stromaticum isolates in laboratory experiments. Once established that the members of the T. stromaticum collection under study could be classified into two major genetic groups (I and II), several phenotypic parameters were assessed to verify to what extent such a genetic classification could be translated into biological behavior. Mycelial growth and sporulation for all $91 \mathrm{~T}$. stromaticum isolates was studied on two different culture media, CMA and PDA, at 25,30 , and $35^{\circ} \mathrm{C}$. None of the isolates were able to grow on both media at $35^{\circ} \mathrm{C}$. On 
CMA, there was a significant difference $(P<0.001)$ in growth rate of isolates from groups I and II at 25 and $30^{\circ} \mathrm{C}$ (Fig. 3). Growth rates of group II isolates were similar at 25 and $30^{\circ} \mathrm{C}(P>$ $0.1)$, whereas group I isolates grew significantly less $(P<0.001)$ at $30^{\circ} \mathrm{C}$ than at $25^{\circ} \mathrm{C}$. On PDA, no significant differences in growth rates were observed between both groups for each temperature $(P>0.1)$, although a significant reduction $(P<0.001)$ in growth was observed at $30^{\circ} \mathrm{C}$ (Fig. 3). Sporulation was examined by visual inspection after 14 days of incubation on both media and at both temperatures (data not shown). At $25^{\circ} \mathrm{C}$, all isolates sporulated on both media. However, at $30^{\circ} \mathrm{C}$ only about $55 \%$ of

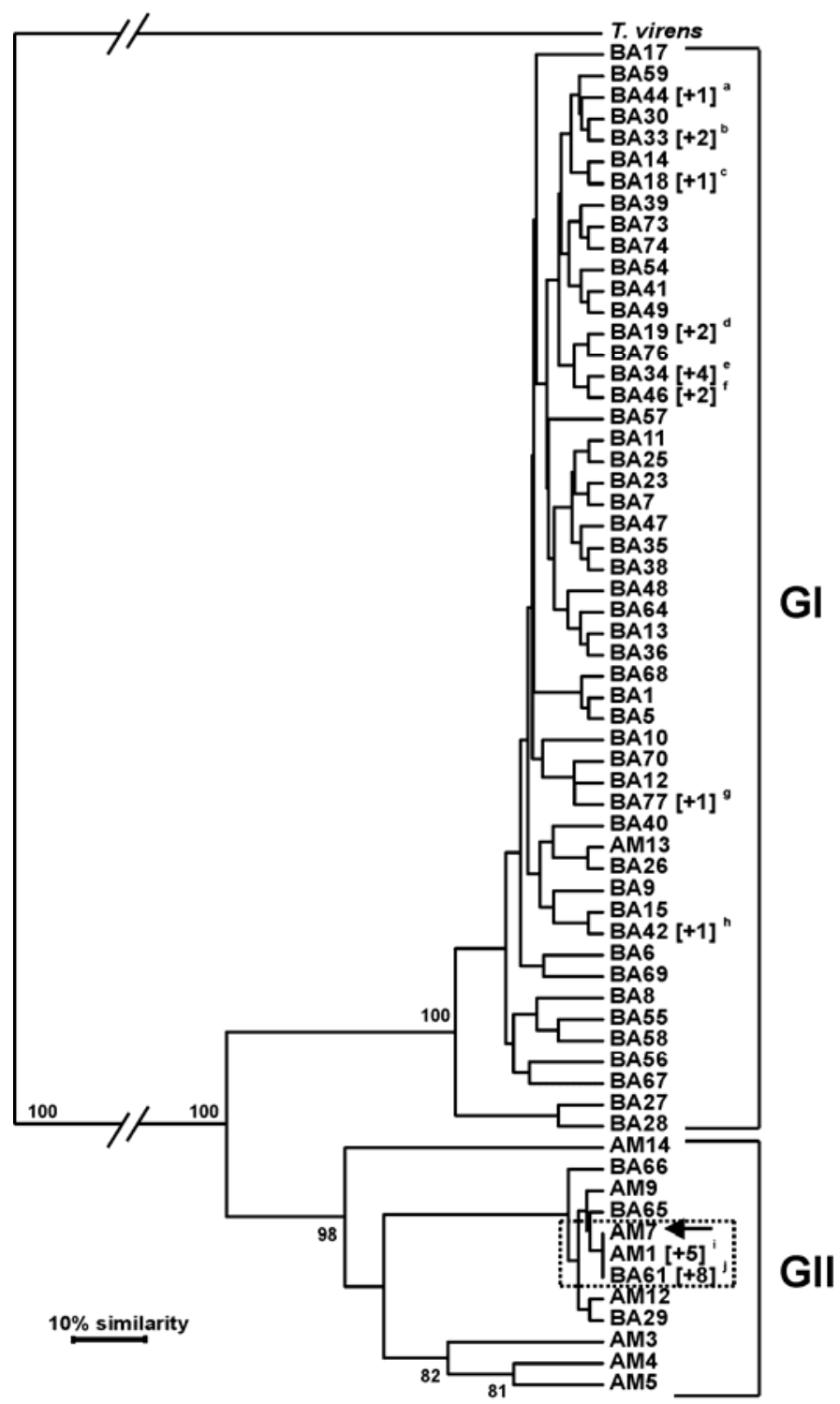

Fig. 2. Genetic diversity of 91 Trichoderma stromaticum isolates based on amplified fragment length polymorphism (AFLP) analysis with the CEQ system. The unweighted pair-group method with arithmetic average with Jaccard's coefficient was used to construct the dendrogram. Numbers in brackets indicate additional members (isolates) in a given AFLP branch, which represents a unique genotype defined on the basis of $100 \%$ similarity among its members, where ${ }^{\mathrm{a}} \mathrm{BA} 37 ;{ }^{\mathrm{b}} \mathrm{BA} 31$ and BA60; ${ }^{\mathrm{c}} \mathrm{BA} 16 ;{ }^{\mathrm{d}} \mathrm{BA} 20$ and BA50; ${ }^{\mathrm{e}}$ BA2 to BA4; ${ }^{\mathrm{B}} \mathrm{BA} 32$ and BA43; $\mathrm{g}$ BA75; ${ }^{\mathrm{h}} \mathrm{BA} 45 ;{ }^{\mathrm{i}} \mathrm{AM} 1, \mathrm{AM} 2, \mathrm{AM} 6, \mathrm{AM} 11$, and AM12; and ${ }^{\mathrm{j}}$ BA21, BA22, BA52, BA53, BA62, BA63, BA65, and BA71. Isolates with codes beginning with BA were obtained in Bahia State and the isolates beginning with AM in the Amazonian region, including the Brazilian States of Rondônia and Pará, Ecuador, Peru, and Colombia. The arrow indicates the isolate that is being marketed and applied in the field. Isolates in the dotted box are genetically equal. T. virens was used as an outgroup. Bootstrap values were based on 1,000 resamplings, and only values higher than $70 \%$ are shown at the appropriate branching points. group I isolates sporulated on CMA and none were able to sporulate on PDA, whereas all isolates from group II sporulated on both media, with the exception of isolate AM3, which was unable to sporulate on CMA at this temperature. A repeated experiment showed similar results.

Sporulation on rice grains was evaluated for $30 \mathrm{~T}$. stromaticum isolates, 17 from group I and 13 from group II (Fig. 4). Since spores of this biocontrol agent are commercially produced on rice grains, it was important to compare sporulation levels of both AFLP-derived groups in this substrate. Isolates from group II produced 1,000-fold more spores than isolates from group I (Fig. $4 \mathrm{~A})$. On infected broom pieces inoculated in the laboratory, there was no difference in sporulation between isolates from groups I and II $(P>0.1)$ at $25^{\circ} \mathrm{C}$ (Fig. $\left.4 \mathrm{~A}\right)$. At $30^{\circ} \mathrm{C}$, however, isolates from group II had higher sporulation $(P<0.001)$ than those from group I. Both AFLP-defined groups showed a generally lower sporulation at $30^{\circ} \mathrm{C}$ than at $25^{\circ} \mathrm{C}(P<0.001)$. On these infected broom pieces, all tested isolates from both groups were capable of killing $C$. perniciosa and block the emergence of its white mycelium at both 25 and $30^{\circ} \mathrm{C}$ (Fig. 4B). Similar results were obtained when these experiments were repeated.

Sporulation of $\boldsymbol{T}$. stromaticum under field conditions. A total of 57 isolates belonging to both AFLP-defined groups were as-

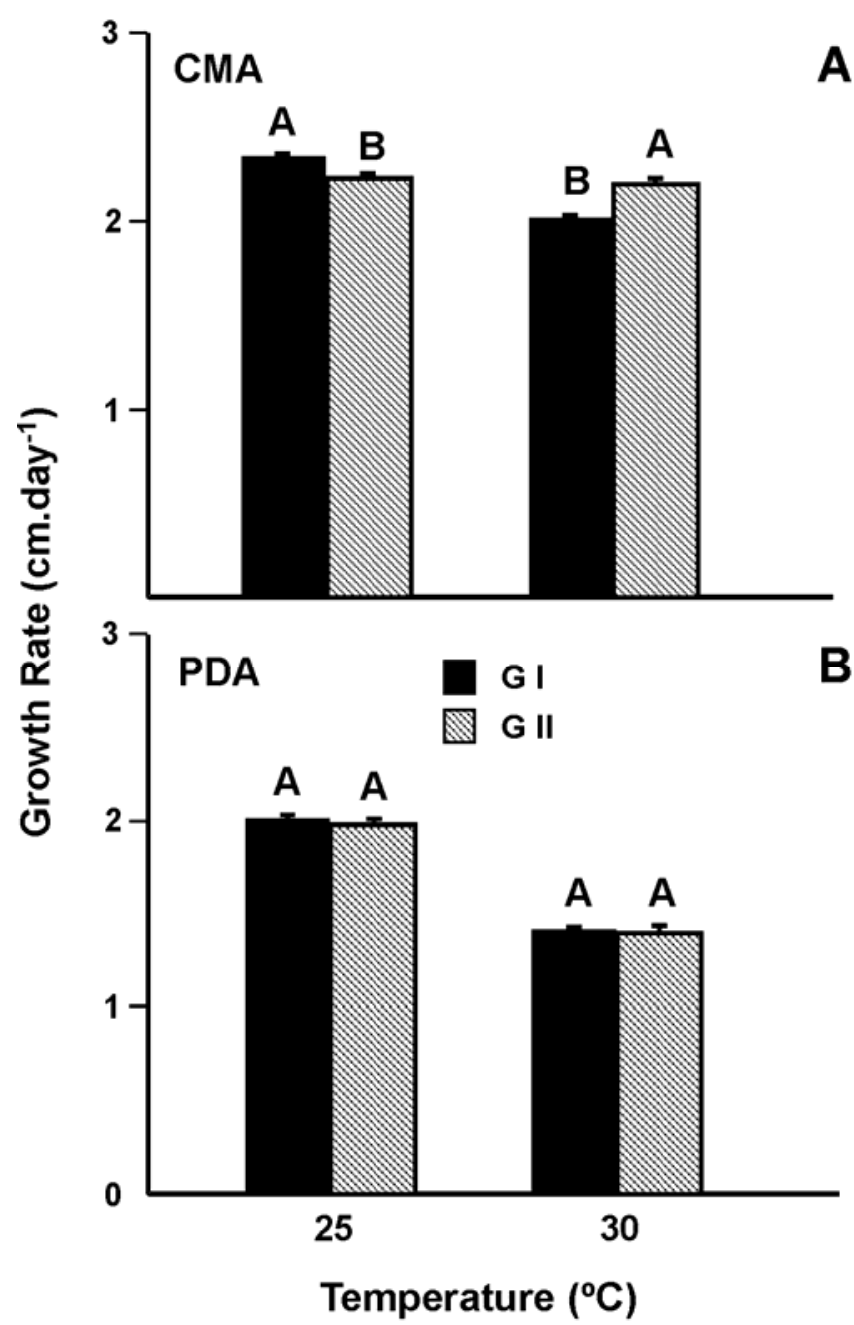

Fig. 3. Growth of the Trichoderma stromaticum genetic groups in different media and temperatures. The average growth rate of the group I (66 isolates) and group II (25 isolates) were compared on $\mathbf{A}$, corn meal agar (CMA) and $\mathbf{B}$, potato dextrose agar (PDA), at 25 and $30^{\circ} \mathrm{C}$. Growth was measured every day until the plate was fully covered. Statistical significance was evaluated according to Wilcoxon's two-sample test $(P=0.05)$. Bars represent the standard error of the means; the experiment had four replicates per isolate and was performed twice. 
sessed during a 3-month trial period. The results showed that the average sporulation incidence was not significantly different $(P>$ 0.1 ) for group I and II isolates and occurred on 45.6 and $47.6 \%$ of inoculated brooms, respectively. No sporulation was observed on the control brooms. T. stromaticum isolates began to sporulate on the brooms about 10 days after the trial started and a decrease in sporulation was observed after the second month for most of the isolates. Similar results were obtained in a repeated experiment.

\section{DISCUSSION}

The mycoparasite $T$. stromaticum has been used in the field as a biocontrol agent of the cacao witches'-broom pathogen $C$. perniciosa since its introduction in Bahia by CEPLAC in 1995 (4). The isolate used, known as TVC (AM7 in this study), was obtained from the State of Pará, located in another cacao-growing area in the Amazon region, approximately 2,300 km from Bahia. Since 1999, isolate AM7 has been marketed by CEPLAC as one of the tools in an integrated pest management strategy for suppressing the witches'-broom disease and has been sprayed in many commercial cacao farms. In our work, we studied the diver-

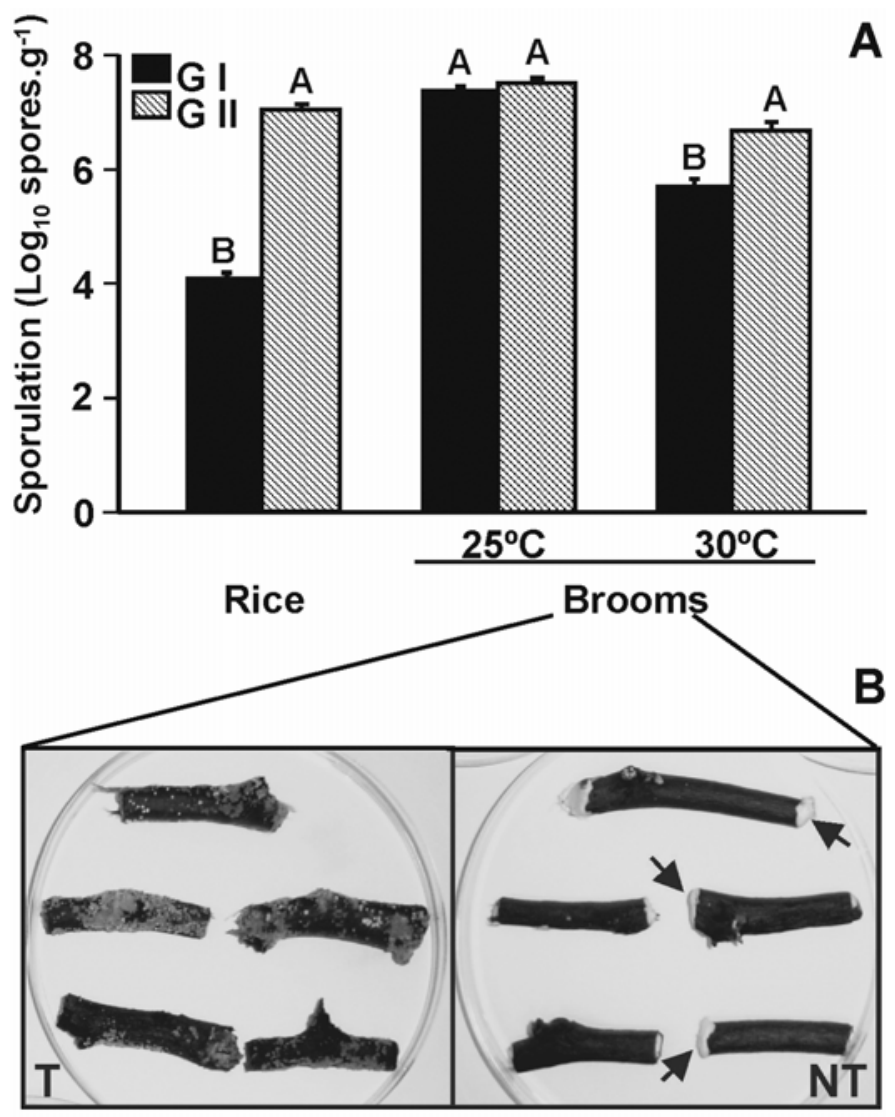

Fig. 4. Sporulation of Trichoderma stromaticum on different substrates and antagonism against Crinipellis perniciosa. A, Isolates were grown in vitro, either on autoclaved rice grains for 10 days, at room temperature, or on broom pieces at 25 and $30^{\circ} \mathrm{C}$. After 10 days of incubation on rice, and 5 days on brooms, the average amount of spores for the groups I (17 isolates) and II (13 isolates) were determined with a hemacytometer. Statistical significance was evaluated according to Wilcoxon's test $(P=0.05)$. Bars represent the standard error of the means; the experiment had four replicates per isolate and was performed twice. B, The picture shows the antagonistic effect against $C$. pernicios $a$ obtained for the 30 isolates tested. Brooms were cut in $3-\mathrm{cm}$ pieces; treated brooms (T) were immersed in spore suspensions of different T. stromaticum isolates, whereas nontreated ones (NT) were dipped in water. Both sporulation of $T$. stromaticum and emergence of $C$. perniciosa mycelium were evaluated 5 days after incubation at $25^{\circ} \mathrm{C}$. Sporulation of $T$. stromaticum can be observed on the surface of treated broom pieces; arrowheads point to the emergence of typical white mycelium of $C$. perniciosa at the ends of nontreated broom pieces. sity of this mycoparasite in the State of Bahia, the main Brazilian cacao-producing area. Our sampling (Fig. 1) focused on abandoned farms where AM7 was supposedly never applied to avoid skewing the sampling toward this isolate.

AFLP studies with the CEQ system showed that $T$. stromaticum isolates from Bahia State could be classified into two genetic groups, here called groups I and II (Fig. 2). The AFLP analysis was also conducted with the MegaBACE 1000 system (Amersham Biosciences, Piscataway, NJ) with similar results (data not shown). AFLP analyses proved to be very consistent, confirming results obtained by other authors (8). Our findings clearly showed that group I has a more widespread occurrence compared with group II. In another survey done in areas sprayed with isolate AM7, both groups I and II could be isolated from all collection sites, although a higher number of group I isolates was recovered (data not shown). One possible reason for the more widespread occurrence of group I isolates is a supposedly higher competitive ability of this group. Alternatively, a more ancient introduction of group I might have occurred, favoring its establishment and spread in the region. This hypothesis is supported by the fact that all isolates from group II found in Bahia were grouped in the subcluster of isolate AM7, indicating that diversity within this subcluster is lower than diversity within group I (Fig. 2).

Isolates BA66 and BA65 in group II that are slightly different from AM7 based on AFLP were found on nonsprayed farms. These isolates either originated from AM7 through mutations or are the result of other introductions. Isolates from group I have never been intentionally introduced in Bahia and the discovery of one representative of group I (AM13) in Colombia (Fig. 2, Table 1), suggests that group I and possibly group II, other than AM7, were introduced in Bahia in association with cacao germ plasm from the Amazonian region. Work by our group and by CABI Bioscience (Ascot, UK) shows that $T$. stromaticum can be isolated from the interior of different parts of cacao trees. In fact, some of the isolates from group II (AM1, AM3, and BA66) used in this study were obtained from different parts of cacao and cupuassu trees (described previously). It is interesting to note that only isolates from group II have been thus far isolated from inside cacao trees, although no extensive surveys have been done. Studies on the endophytic ability and significance of this behavior in $T$. stromaticum are currently being conducted by our research group.

Another interesting finding in the AFLP studies was the higher level of diversity among isolates from group II. Although we have no data at this point to draw any conclusions, this may indicate an earlier origin of group II in relation to group I. This hypothesis and the separation into groups I and II were not supported by the analysis of rDNA sequences, although the analysis was sensitive enough to confirm the identity of $T$. stromaticum. The rDNA sequences, however, are known to have low resolving power for phylogenetic studies of closely related organisms (5) and other genes are often more informative (10). It is interesting to note that all T. stromaticum rDNA sequences available in the public databases prior to this work were from group II isolates obtained in the Brazilian Amazonian region, which were all included in our AFLP analyses.

In vitro experiments confirmed the separation of $T$. stromaticum into groups I and II. The results showed that both groups grew differently only on the nutrient-poor CMA, but not on the nutrient-rich PDA. One possible explanation for the faster growth of both groups on CMA is the rapid depletion of the medium, whereas PDA sustains growth of the mycelium for longer periods in the same area.

The lower growth rate and sporulation observed for group I at $30^{\circ} \mathrm{C}$ compared with $25^{\circ} \mathrm{C}$, both on culture media and broom pieces, as well as on rice grains (Figs. 3 and 4) suggests sensitivity of this group to higher temperatures. Therefore, it is reasonable to expect that isolates from group II would be more adapted 
to field conditions with higher amplitudes of temperature, which is an important parameter to consider when devising biological control strategies.

Despite the differences in the behavior of groups I and II in vitro, no significant differences were observed in the field experiments with regard to their sporulation on brooms. This finding might be explained by the supposedly lower temperatures under the canopy of the cacao trees, which in turn are under the cabruca system. During the experiment, the mean temperature was $23.5^{\circ} \mathrm{C}$ for the first month and $20.7^{\circ} \mathrm{C}$ for the second. These data were taken from a weather station located $300 \mathrm{~m}$ from the area where the experiment was done. These temperatures might have been conducive for sporulation of both genetic groups, therefore explaining the lack of difference between them.

It will be interesting to study the performance and natural spread of isolates from groups I and II under field conditions. Preliminary data from our research team indicate that isolates from group I are more efficient in dispersal than the isolates from group II (J. T. de Souza, unpublished data). However, problems with mass production will certainly arise if isolates from group I were chosen to be applied in the field because of their poor ability to sporulate on rice grains, the substrate used to produce inoculum for field applications. Work is in progress using molecular markers to study the epidemiology of these two groups and their effect on disease suppression. Ultimately, this work will be of fundamental importance for the selection of an efficient strain for managing witches'-broom disease in Brazil and other cacaoproducing countries.

\section{ACKNOWLEDGMENTS}

We thank G. Samuels, C. Bastos, H. Evans, and K. Holmes for providing isolates of T. stromaticum from the Amazonian region; M. Montargil, L. dos Santos, A. Guimarães, and C.-S. Decker for technical assistance; R. Lumsden for critical review of the manuscript; and M. Aitken for supporting the field collection of isolates.

\section{LITERATURE CITED}

1. Andebrhan, T., Figueira, A., Yamada, M. M., Cascardo, J., and Furtek, D. B. 1999. Molecular fingerprinting suggests two primary outbreaks of witches' broom disease (Crinipellis perniciosa) of Theobroma cacao in Bahia, Brazil. Eur. J. Plant Pathol. 105:167-175.

2. Bastos, C. N. 1996. Potencial de Trichoderma viride no controle da vassoura-de-bruxa (Crinipellis perniciosa) do cacaueiro. Fitopatol. Bras. 21:509-512.

3. Bastos, C. N., Evans, H. C., and Samson, R. A. 1981. A new hyperparasitic fungus, Cladobotryum amazonense, with potential for the control of fungal pathogens of cocoa. Trans. Br. Mycol. Soc. 77:273-278.

4. Costa, J. C. B., Bezerra, J. L., and Cazorla, I. M. 1996. Controle biológico da vassoura-de-bruxa do cacueiro na Bahia com Trichoderma polysporum. Fitopatol. Bras. 21:397.
5. Fox, G. E., Wisotzkey, J. D., and Jurtshuk, P., Jr. 1992. How close is close: 16S rRNA sequence identity may not be sufficient to guarantee species identity. Int. J. Syst. Bacteriol. 42:166-170.

6. Griffith, G. W., Nicholson, J., Nenninger, A., Birch, R. N., and Hedger, J. N. 2003. Witches' brooms and frosty pods: Two major pathogens of cacao. New Zeal. J. Bot. 41:423-435.

7. Hampl, V., Pavlicek, A., and Flegr, J. 2001. Construction and bootstrap analysis of DNA fingerprinting-based phylogenetic trees with the freeware program FreeTree: Application to trichomonad parasites. Int. J. Syst. Evol. Microbiol. 51:731-735.

8. Jones, C. K., Edwards, K. J., Castaglione, S., Winfield, M. O., Sala, F., van de Wiel, C., Bredemeijer, G., Vosman, B., Matthes, M., Daly, A., Brettschneider, R., Bettini, P., Buiatti, M., Maestri, E., Malcevschi, A., Marmiroli, N., Aert, R., Volckaert, G., Rueda, J., Linacero, R., Vazquez, A., and Karp, A. 1997. Reproducibility testing of RAPD, AFLP and SSR markers in plants by a network of European laboratories. Mol. Breed. 3:381-390.

9. Jukes, T. H., and Cantor, C. R. 1969. Evolution of protein molecules. Pages 21-132 in: Mammalian Protein Metabolism. Academic Press, New York.

10. Kullnig-Gradinger, C. M., Szakacs, G., and Kubicek, C. P. 2002. Phylogeny and evolution of the genus Trichoderma: A multigene approach. Mycol. Res. 106:757-767.

11. Kumar, S., Tamura, K., Jakobsen, I. B., and Nei, M. 2001. MEGA2: Molecular evolutionary genetics analysis software. Bioinformatics 17:1244-1245.

12. Laas, R. A. 1985. Diseases. Pages 265-365 in: Cocoa. 4th ed. Longmans, London, UK.

13. Page, R. D. M. 1996. TREEVIEW: An application to display phylogenetic trees on personal computers. Comp. Appl. Biosci. 12:357-358.

14. Papavizas, G. C., and Lumsden, R. D. 1982. Improved medium for isolation of Trichoderma spp. from soil. Plant Dis. 66:1019-1020.

15. Pereira, J. L. A., De Almeida, L. C. C., and Santos, S. M. 1996. Witches' broom disease of cocoa in Bahia: Attempts at eradication and containment. Crop Prot. 15:743-752.

16. Rudgard, S. A., and Butler, D. R. 1987. Witches' broom disease in Rondonia, Brazil: Pod infection in relation to pod susceptibility, wetness, inoculum, and phytosanitation. Plant Pathol. 36:515-522.

17. Sambrook, J., and Russel, D. W. 2001. Molecular Cloning: A Laboratory Manual. 3rd ed. Cold Spring Harbor Laboratory, Cold Spring Harbor, NY.

18. Samuels, G. J., Pardo-Schultheiss, R., Hebbar, K. P., Lumsden, R. D., Bastos, C. N., Costa, J. C., and Bezerra, J. L. 2000. Trichoderma stromaticum sp. nov., a parasite of the cacao witches broom pathogen. Mycol. Res. 104:760-764.

19. Sanogo, S., Pomella, A. W. V., Hebbar, P. K., Bailey, B., Costa, J. C. B., Samuels, G. J., and Lumsden, R. D. 2002. Production and germination of conidia of Trichoderma stromaticum, a mycoparasite of Crinipellis perniciosa on cacao. Phytopathology 92:1032-1037.

20. Saunders, J. A., Pedroni, M. J., Penrose, L. D. J., and Fist, A. J. 2001. AFLP Analysis of opium poppy. Crop Sci. 41:1596-1601.

21. Thompson, J. D., Higgins, D. G., and Gibson, T. J. 1994. CLUSTAL W: Improving the sensitivity of progressive multiple alignment through sequence weighting, position-specific gap penalties and weight matrix choice. Nucleic Acids Res. 22:4673-4680.

22. Wheeler, B. E. J. 1985. The growth of Crinipellis perniciosa in living and dead cocoa tissue. Pages 103-116 in: Developmental Biology of Higher Fungi. Cambridge University Press, London, UK.

23. White, T. J., Bruns, T., Lee, S., and Taylor, J. 1990. Amplification and direct sequencing of fungal ribosomal RNA genes for phylogenetics. Pages 315-322 in: PCR Protocols: A Guide to Methods and Applications. Academic Press, San Diego. 